\title{
THE ENERGY EXPENDITURE OF COAL-MINERS AT WORK
}

\author{
BY \\ P. W. HUMPHREYS and A. R. LIND \\ with the technical assistance of \\ K. S. SWEETLAND \\ From the National Coal Board Physiology Research Group, Department of Human \\ Anatomy, University of Oxford
}

(RECEIVED FOR PUBLICATION MAY 25, 1962)

\begin{abstract}
This survey was intended to provide a basis of information on the energy expenditures for the main component tasks in coal-mining, carried out at different rates and in different postures. Such information is frequently required for studies of the physiological effects of coal-mining; these values reported here were required in particular for studies intended to define thermal limits of the environment suitable for miners at non-mechanized coal-faces, a situation where the metabolic heat produced makes up a large proportion of the total heat load of the individual.

Regression lines have been drawn between energy expenditure and speed of shovelling for the miner working in different postures. When forced to work lying on the floor the man's energy expenditure dropped, but his coal output also dropped. Walking to and from the coal-face along roadways of good height yielded energy expenditures comparable to those of treadmill walking, although generally slightly higher in value. Stooped walking generally increased the energy expenditure of walking, but to a smaller extent than was anticipated from previous laboratory work.

Several time analyses of complete shifts from different collieries, in which the time spent at different tasks had been measured, yielded an average estimate of the energy expenditure for an eight-hour shift of $2,000 \mathrm{kcal}$.
\end{abstract}

The coal-mining industry of Great Britain, one of the largest "heavy" industries in the world, employs well over two hundred thousand men at the coal-face alone, and more than that number elsewhere underground. Many among this large labour force expend energy daily in quantities that are greater than in most other large industrial concerns. A need to be able to estimate the energy production of miners working in different collieries, where physical conditions and the rate and pattern of work vary, led to the present investigation; it forms an integral part of a programme of research intended to determine thermal environmental conditions for everyday work at the coal-face (Lind, 1960) in which the contribution of metabolic heat to the total heat load would certainly be substantial. For this purpose it is desirable to know not only the man's total energy production in the course of a shift, but also the extent to which it varies from hour to hour.
Generally, the measurement of energy expenditure of man in the course of his daily activities has been related either to his food requirements, or to the rearrangement of his work in such a way as to permit greater efficiency and productivity, coupled, if possible, with a reduction in the physiological strain. For these reasons the energy expenditures involved in some mining tasks have previously been reported from the East Midlands by Moss (1935), from Germany by Lehmann, Müller, and Spitzer (1950), and from Italy by Granati and Busca (1941). These earlier investigations into the energy cost of coal-mining are not entirely satisfactory as working conditions have changed much since the time of Moss, and foreign surveys made on men subjected to food rationing would certainly not be expected to reflect modern conditions in this country.

A more recent survey has been made in an East Fife colliery (Garry, Passmore, Warnock, and 
Durnin, 1955), where measurements were made of a number of underground activities during actual production mining, and estimates were produced for the energy cost of complete shifts of work. How far such results from a single colliery may be considered representative of work in any other colliery is uncertain: physical conditions such as the height of the seams vary greatly from face to face, even in the same colliery, and these in turn affect the miner's posture and his rate of work. It was, therefore, considered necessary to make a more comprehensive survey, where these factors could be studied. Whereas previous studies were made in actual production mining conditions during which the rate of work could not be controlled, in the present investigation facilities were provided underground allowing the observers to regulate both the rate of the particular activity to be measured and the posture adopted. Thus, with sufficient information on the effect on energy expenditure of these important variables, it ought to be possible to make reasonable estimates of the hourly and the total metabolic heat production of any faceworker at any colliery, by measuring the time spent on the various component tasks, and then substituting the appropriate values of energy expenditure.

Previously, in a series of time analyses of complete shifts, carried out at $\mathbf{1 6}$ different coal-faces in different parts of the country, it was established that when all the required stint of coal was loaded, about $40 \%$ of the shift was spent either sitting or standing, principally because the men were unable to work due to conveyor belt stoppages, $30 \%$ was spent shovelling coal, and about $15 \%$ was spent walking to and from the face. Since there is sufficient information on the energy expenditure of resting men, it was decided here to concentrate on tasks with a high energy expenditure, i.e. shovelling, hewing, and walking.

\section{Methods}

Facilities and subjects for this work were provided at Waterloo Colliery, Monmouthshire.

A total of 14 subjects took part; their ages, heights, and weights are given in Table 1 . The 10 subjects used for work at the coal-face were hand fillers, i.e. men whose main occupation is loading coal with a shovel onto a conveyor belt. Eight of them were fully experienced fillers who had been working at this colliery for several years; the remaining two, $S$ and $H$, were spare fillers who had worked from time to time at the coal-face for the previous two years. The other four subjects, E, J, L, and $R$, used for a detailed study of walking were not coal-face workers although they were employed underground. All subjects were fully experienced in any work which they were asked to do in this survey.

The subjects were asked to work at a steady pace at the different tasks in turn, and the conditions under
TABLE 1

SUBJECTS' AGE, WEIGHT, AND HEIGHT

\begin{tabular}{c|c|c|c}
\hline Subject & $\begin{array}{c}\text { Age } \\
\text { (years) }\end{array}$ & $\begin{array}{c}\text { Weight } \\
\text { (kg.) }\end{array}$ & $\begin{array}{c}\text { Height } \\
\text { (cm.) }\end{array}$ \\
\hline C & 37 & 63.73 & 163.6 \\
G & 37 & 60.56 & 163.6 \\
T & 37 & 88.00 & 179.0 \\
I & 27 & 60.56 & 168.5 \\
F & 45 & 68.95 & 162.6 \\
H & 23 & 77.11 & 166.6 \\
Q & 24 & 82.87 & 171.0 \\
O & 51 & 73.71 & 166.4 \\
P & 23 & 59.65 & 168.4 \\
E & 27 & 68.95 & 167.4 \\
J & 23 & 55.25 & 163.8 \\
R & 25 & 66.45 & 172.7 \\
L & 35 & 92.99 & 167.9 \\
\hline
\end{tabular}

which each man worked were kept as similar as possible. The coal had to be loaded onto a conveyor belt 9 to 12 in. from the floor, except where otherwise mentioned, and the miners were asked to clear coal from the floor for a distance of up to 1 yard horizontally from the belt; a photograph of a miner loading coal under these conditions is shown in Fig. 1. During different trials the men were asked to shovel at different paces; an observer assessed the miner's rate of work by counting the number of shovel-loads of coal moved each minute. Measurements of the energy expenditure during shovelling were made with miners (i) standing, (ii) kneeling, and (iii) lying on the floor. In the last case it was not possible for the men to work other than at their own normal pace, although the rate was again measured.

It was impossible for the observers to make any attempt at quantitative measurement of the work done during hewing, illustrated in Fig. 2, and the men set their own normal pace, adjusted to the physical condition of the coal, at this task. Measurements were made with the subject working while lying on the floor and working either standing or kneeling.

Walking included walking up and down two gradients, $1: 20(5 \%)$ and $1: 8.8(11 \cdot 4 \%)$, as well as on the level in each of three postures: upright, with a slight stoop which reduced the miner's height by about $20 \%$, and with a full stoop which reduced the miner's height by about $40 \%$; the postures are shown in Fig. 3. Underfoot conditions were good for level walking, average for underground on the $1: 20$, and bad and wet for the $1: 8.8$, as shown in Fig. 3. Gradients were calculated from changes in height for a given distance using a surveyor's plan of the colliery. In each trial the subject was paced by an observer. The pace set was different for every gradient and for every posture, so that the speeds were typical in each case for miners walking in the relevant underground conditions; the measured speeds are shown in Table 3 in the presentation of the results. (The subjects agreed that the speeds were typical.) To pace the subjects the observer used a stop-watch and checked the time at markers placed on the roadway at 100 -ft. intervals, so that variations in pace were minimal for any given task.

An observer accompanied each subject at work, and often two observers were necessary. At any given task 


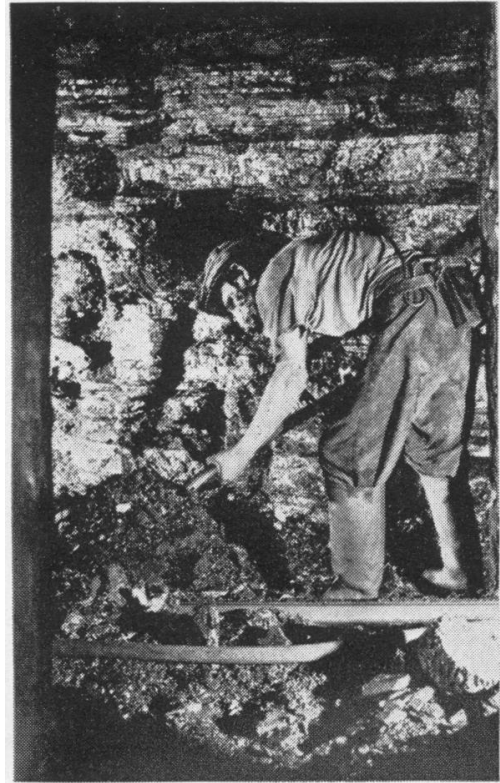

FIG. 1.-Miner loading coal onto conveyor belt.

the first five minutes were considered more than adequate for work rate and energy expenditure to become steady; after this warming-up period measurements were begun. Before walking with a full stoop, because of the tiring

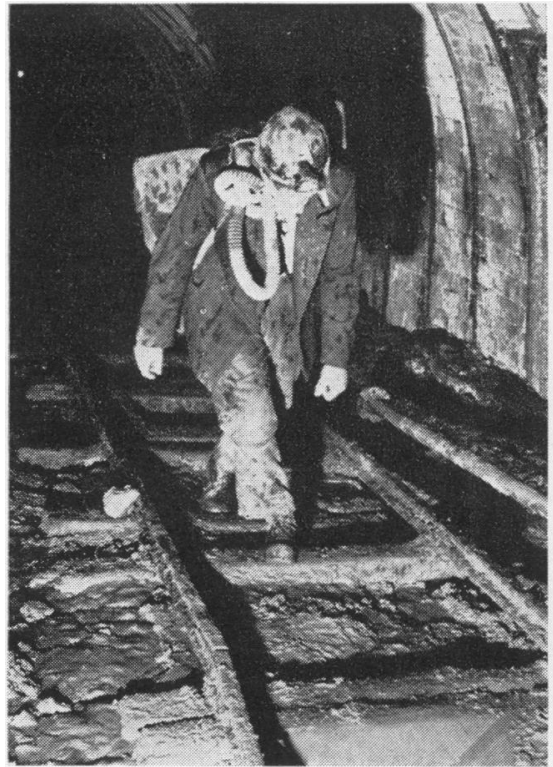

a

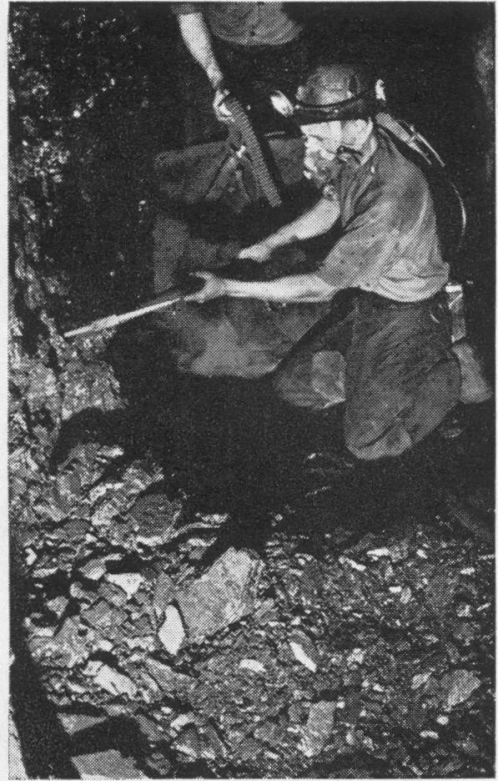

Fig. 2.-Miner hewing.

effect of the static effort involved, the subjects were allowed to spend the first half of the warming-up period at another walking task estimated to incur a similar energy expenditure. Similarly, due to the limited length

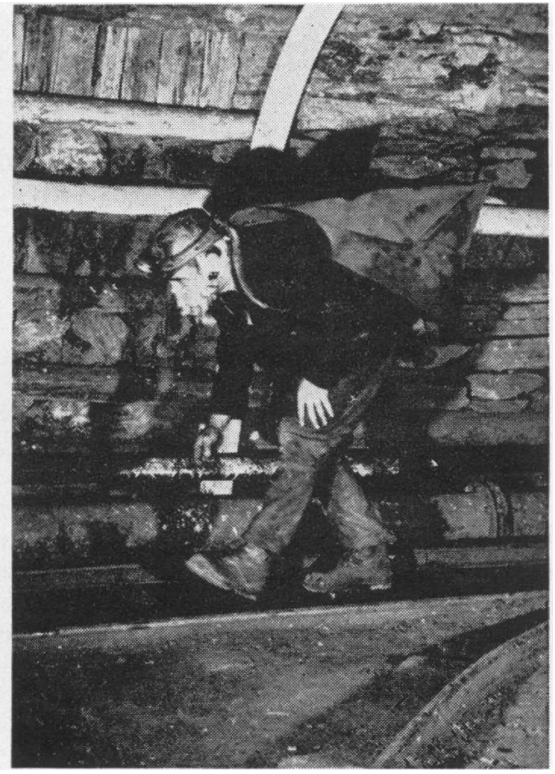

b

FIG. 3.-a. Miner walking up $1: 8.8$ gradient with a slight stoop. b. Miner walking on the level with a full stoop. 


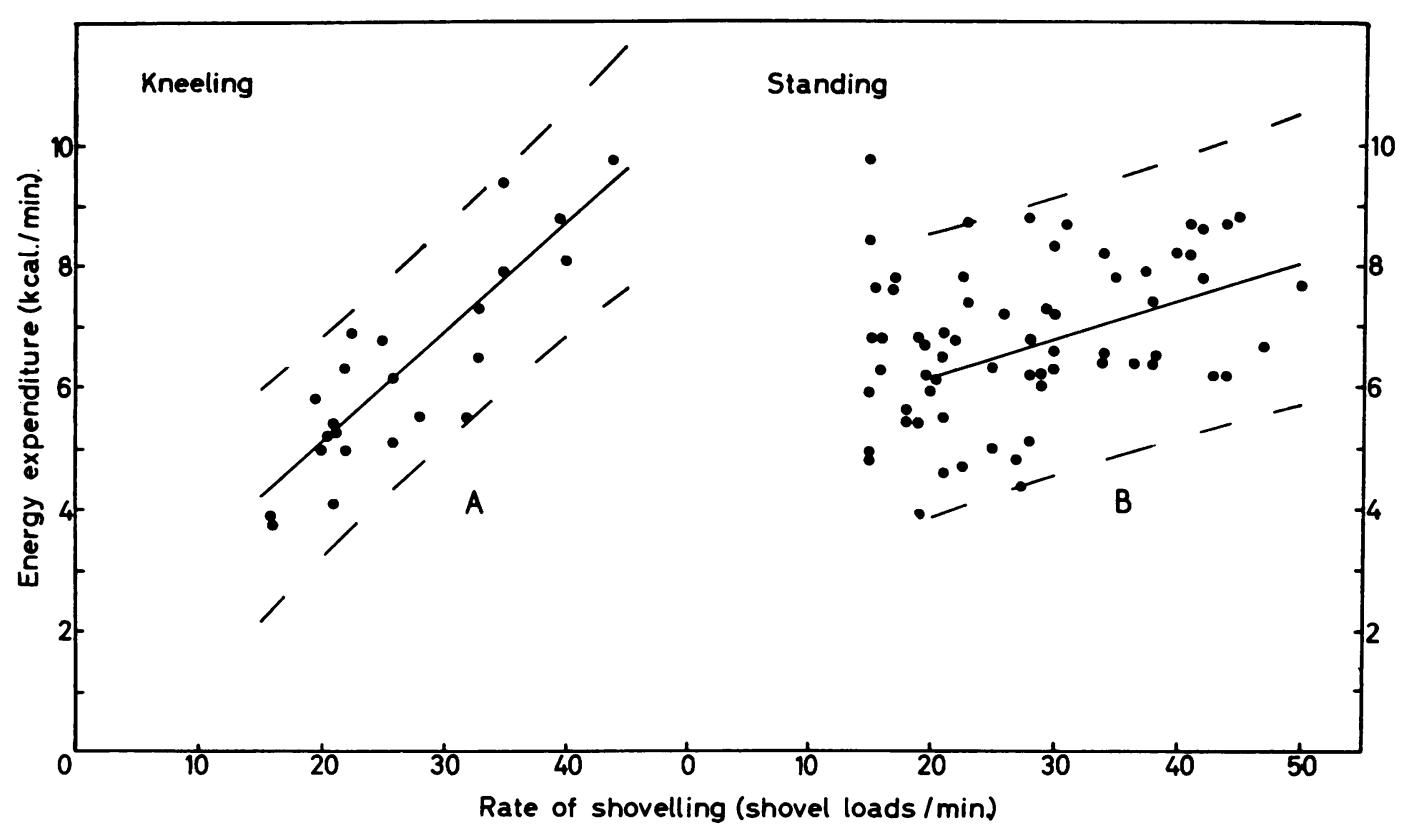

FIG. 4.-Energy expenditure for shovelling at different rates-(a) kneeling, (b) standing: together with regression lines and their (curvilinear) $95^{\circ}$ o confidence limits of prediction.

(400 yards) of the inclines, the early part of the warming-up period for gradient walking was spent walking in the opposite direction at a rate estimated to incur a similar energy expenditure.

After preliminary trials it was decided to use the traditional technique of collecting the expired air in a Douglas bag. Other methods of collection were rejected and delays which might have occurred during maintenance of the respirometers were avoided. The subjects wore R.A.F. ' $H$ ' type face masks modified as for use with the integrating motor pneumotachograph (I.M.P.) (Wolff, 1958); a lightweight Perspex spring-loaded valve as supplied with the Kofrányi and Michaelis (1940) meter directed the expired air from the mask into a Douglas bag either held by an observer or, in walking tasks, carried by the subject. The Douglas bag was afterwards emptied through a K.M. meter-used in this investigation as a portable dry gas meter-and a sample of the expired air was stored in a sample tin as supplied for use with the I.M.P., except that the inner plastic bags were replaced by butyl rubber bags to ensure doubly against any significant exchange of gases. The analysis of the expired air samples was made using the Lloyd gas analysis apparatus, a modified form of the Haldane apparatus (Lloyd, 1958). The calibration factor of the K.M. meter was checked daily, and did not vary by more than $1 / 100$. Barometric readings were taken daily both underground and at the surface.

\section{Results}

Each individual result obtained in the survey is tabulated in the Appendix at the end of this report.
The standard deviation of each result quoted was virtually independent of the task being studied and of the subject; its average value was $0.6 \mathrm{kcal} . / \mathrm{min}$. Therefore, in the following presentation of results averages are presented for particular tasks, irrespective of subject. For individual subjects, expenditures of energy throughout the range of tasks were found to be neither consistently high nor consistently low, although for certain groups of tasks there were some patterns of consistency.

Some statistical aspects of the results are described elsewhere by Liddell (1962).

Loading Coal.-Four subjects, C, G, I, and T, who worked on their knees, yielded the 22 results shown in Fig. 4, where energy expenditure is plotted against speed of shovelling, measured in shovelfuls of coal/ min. A regression line has been drawn whose equation is

$$
E=1.34+0.19 r \ldots \ldots \ldots \text { (1) }
$$

where $E$ is the kilocalories expended per man per minute, and $r$ is the rate of working in shovelfuls/ min. The standard deviation at the mean rate of work is 0.85 so that the $95 \%$ confidence limits of prediction, shown by the broken lines in Fig. 4, were $\pm 1.78 \mathrm{kcal} . / \mathrm{min}$. at the average rate of shovelling.

Fig. 4 also illustrates the energy expenditures at different rates of shovelling for 10 subjects, $C, G, I$, 
TABLE 2

MEAN ENERGY EXPENDITURE FOR WORK AT COAL-FACE

\begin{tabular}{|c|c|c|c|c|}
\hline Task & $\begin{array}{c}\text { Energy } \\
\text { Expenditure } \\
\text { (kcal./min.) }\end{array}$ & Speed of Work & $\begin{array}{l}\text { Number of } \\
\text { Subjects }\end{array}$ & $\begin{array}{c}\text { Number of } \\
\text { Measurements }\end{array}$ \\
\hline $\begin{array}{l}\text { Loading coal: } \\
\text { On feet } \\
\text { On knees } \\
\text { Lying } \\
\text { On feet with conveyor flush with floor }\end{array}$ & $\begin{array}{l}7 \cdot 0 \\
7 \cdot 0 \\
5 \cdot 3 \\
7 \cdot 5\end{array}$ & $\begin{array}{l}\text { Normal Z } \\
\text { Normal Z } \\
\text { Normal Y } \\
\text { Very fast } \dagger\end{array}$ & $\begin{array}{l}* \\
* \\
4 \\
3\end{array}$ & $\begin{array}{r}* \\
10 \\
5\end{array}$ \\
\hline $\begin{array}{l}\text { Hewing coal: } \\
\text { Either on feet or knees } \\
\text { Lying } \\
\text { Either on feet or knees using pneumatic pick }\end{array}$ & $\begin{array}{l}6 \cdot 1 \\
5 \cdot 3 \\
7 \cdot 1\end{array}$ & $\begin{array}{l}\text { Normal } \\
\text { Normal } \\
\text { Normal }\end{array}$ & $\begin{array}{r}10 \\
4 \\
3\end{array}$ & $\begin{array}{r}27 \\
10 \\
4\end{array}$ \\
\hline
\end{tabular}

$\mathrm{T}, \mathrm{F}, \mathrm{H}, \mathrm{O}, \mathrm{P}, \mathrm{Q}$, and $\mathrm{S}$, who loaded coal while standing. The relation between the energy expenditure and speed of work is significantly $(p>0.05)$ different from that for kneeling subjects; at slow rates of shovelling the energy expenditure was higher than that found when men shovelled on their knees, and at high rates it was lower. Further, in this case, at the lowest rates of shovelling a drop in rate resulted in a rise of energy expenditure, and so the regression line shown in Fig. 4 is limited to rates of 20 shovelfuls/min. and above. It has the equation:

$$
E=4.91+0.06 r \ldots \ldots \ldots(2)
$$

The $95 \%$ confidence limits of prediction from the regression equation, indicated by the broken lines, were $\pm 2.31 \mathrm{kcal} . / \mathrm{min}$. at the mean rate of work. (The scatter about this regression was greater than with the men on their knees, but when only the same four subjects, C, G, I, and T, were considered in both postures, the regression line for men shovelling on their feet had a higher slope so that $E=4 \cdot 12+$ $0.09 r$, and the $95 \%$ confidence limits at the mean rate of work were $\pm 1.87 \mathrm{kcal} . / \mathrm{min}$., i.e. comparable to those for regression (1).)

Comparison of the results in Fig. 4 with those reported in other surveys where the rates and postures of working have not been specified, requires a choice of normal rate of work. During the part of the present investigation dealing with the time analyses of completed underground shifts, it was found that both for kneeling men and standing men, normal rates of shovelling in production conditions where height and distance of throw are the same as in this survey usually approximate to 30 shovelfuls $/ \mathrm{min}$. At this rate of work, energy expenditure for both postures can be seen (Fig. 4) to be about $7 \mathrm{kcal} / / \mathrm{min}$.

When working while lying on their sides, four subjects, $C, G, I$, and $T$, gave a mean energy expenditure of $5.3 \mathrm{kcal} . / \mathrm{min}$. for an average rate of working of 25 shovelfuls/min. (range 19 to 31 shovelfuls/ min.) This is about $1 \mathrm{kcal} . / \mathrm{min}$. less than those given by the regression lines for the other postures at 25 shovelfuls $/ \mathrm{min}$. which were 6.1 and $6.4 \mathrm{kcal}$./ min., or about $1.5 \mathrm{kcal} . / \mathrm{min}$. less than the value of $7 \mathrm{kcal}$./min. deduced above for "normal" rates of work in other postures. At the same time it was obvious to the observers that less coal was being moved.

An additional five measurements were made on three subjects, C, G, and T, with the conveyor belt flush with the floor so that coal could be rapidly dragged or "scooped" onto the belt and the height of throw would be nil. As previously, the coal which was loaded was not more than one yard from the belt. This procedure had an overall energy expenditure of $7.5 \mathrm{kcal} . / \mathrm{min}$. for the high average rate of shovelling of 49 shovelfuls $/ \mathrm{min}$. Although it was not possible to measure the amounts of coal loaded onto the conveyor in this way, the observers estimated that the weight of coal moved per shovel-load during "scooping" was at least as great as when the conventional shovelling method was employed.

The results discussed above are summarized in Table 2, which also, see below, gives those for hewing.

Hewing Coal.-Twenty-seven measurements were made on 10 men, C, G, I, T, F, H, O, P, Q, and S, hewing coal at their own normal pace with a hand pick. The average energy expenditure was $6.1 \mathrm{kcal}$./ min. It was not possible for the observers to make assessments of the work done during hewing, since variations in the condition of the coal were difficult to define. Ten further measurements on the four subjects, $\mathrm{C}, \mathrm{G}, \mathrm{I}$, and $\mathrm{T}$, hewing while lying on their sides gave a lower mean of $5.3 \mathrm{kcal} . / \mathrm{min}$.

Three subjects, G, I, and T, set their own pace at hewing with pneumatic picks; four measurements only were made, which resulted in an average value of $7 \cdot 1 \mathrm{kcal} . / \mathrm{min}$.

Walking Underground.-The results are tabulated in Table 3 which shows the average energy expendi- 
ture for each separate task together with the number of subjects used and the number of estimates on which the average is based. Each task was paced at a speed which the observers and miners considered customary for walking underground in the relevant conditions, so that the speed of each task varied according to the circumstances. (It was later considered that 1.96 m.p.h. is unnecessarily slow for level walking with a full stoop and that $2 \cdot 1$ m.p.h. would be a better approximation.) An exception was made for level walking with normal posture which was paced at two speeds, one a little below the usual one, the other above; this might well be likened to the speeds of "walking in" to the workings and "walking out". A small number of subsidiary records were also made at slow pace uphill walking with normal posture; the purpose of these was solely to ensure that the relation between speed of walking and energy expenditure was similar in these conditions to those of laboratory studies.

As can be seen from Table 3, walking on the level or downhill in any posture at the various paces chosen as normal led to average energy expenditures for the group of men of from 3.9 to $5.5 \mathrm{kcal} . / \mathrm{min}$., and walking uphill, except at artificially slow paces, led to the higher average energy expenditures of from 5.6 to $8.6 \mathrm{kcal} . / \mathrm{min}$. If men stooped when walking up a $1: 8.8$ gradient, the results yielded average energy costs for the group of men of from 6.5 to $8.6 \mathrm{kcal}$. $/ \mathrm{min}$. Stooped walking under the other conditions, i.e. up $1: 20$, level, and downhill walking, yielded energy costs within $0.5 \mathrm{kcal}$. of $5 \cdot 25 \mathrm{kcal}$./min. Slightly stooped level walking was the only exception with an energy cost of $4.0 \mathrm{kcal}$./ min.

Figs. 5, 6, and 7 illustrate results from this investigation together with those of laboratory studies of men walking on treadmills for comparison. In Fig. 5 the average results and ranges for level walking in normal postures (as well as other postures) are shown, superimposed on a curve from the review of Passmore and Durnin (1955) which represents the collective results from several laboratories in Germany, Italy, America, and Britain, of subjects walking on treadmills at different speeds. The energy expenditures of normal posture walking in the present study are in good agreement with the laboratory data, although about $0.5 \mathrm{kcal} . / \mathrm{min}$. higher than the laboratory results.

For men walking uphill in their normal posture the present data are again in good agreement with those from laboratories as is shown in Fig. 6, where the curves are constructed from the results from four subjects examined by Margaria (1938) and two subjects examined by Cotes and Meade (1960). Fig. 7 has been similarly constructed for the results of walking downhill where the present results are again compared with data from Margaria (1938) and Cotes and Meade (1960). Walking down both gradients the values for this survey are about 0.9 $\mathrm{kcal} . / \mathrm{min}$. higher than might have been expected from the results of Margaria (1938) and Cotes and Meade (1960).

Figs. 5, 6, and 7 show that the results for normal posture walking in this survey compare well with the laboratory data for each gradient, and Figs. 5 and 6 confirm that the relation between speed and energy expenditure for walking underground is similar to that for walking on a treadmill. If information is required on the energy expenditure of walking underground at any other speeds that are likely to occur, it is suggested that no large error will be introduced

TABLE 3

MEAN ENERGY EXPENDITURES FOR WALKING TASKS

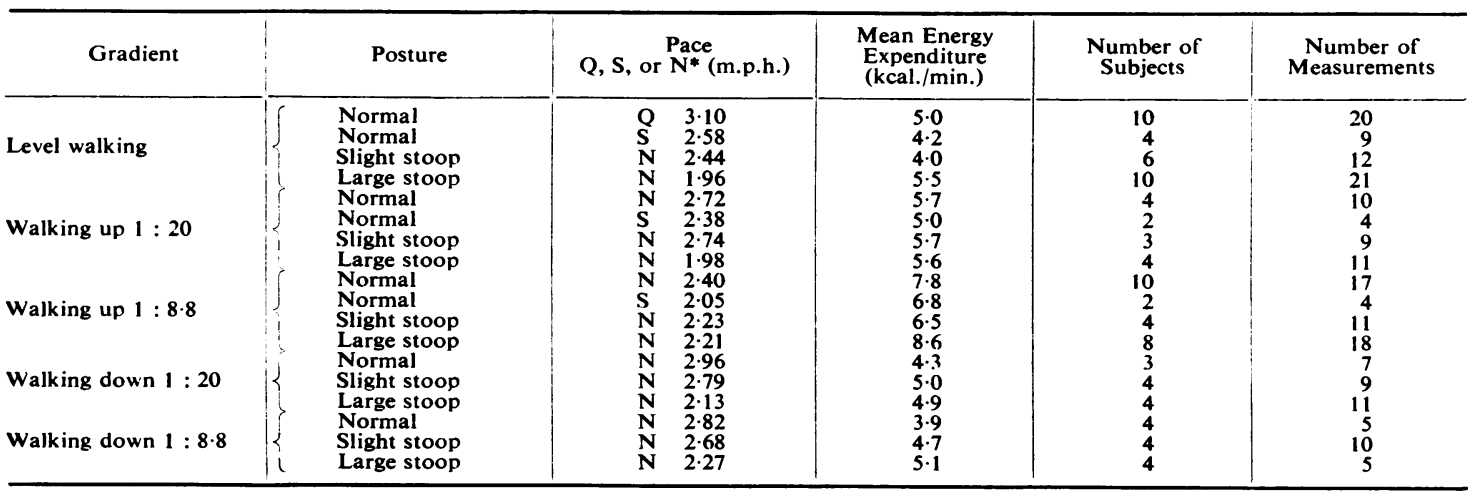




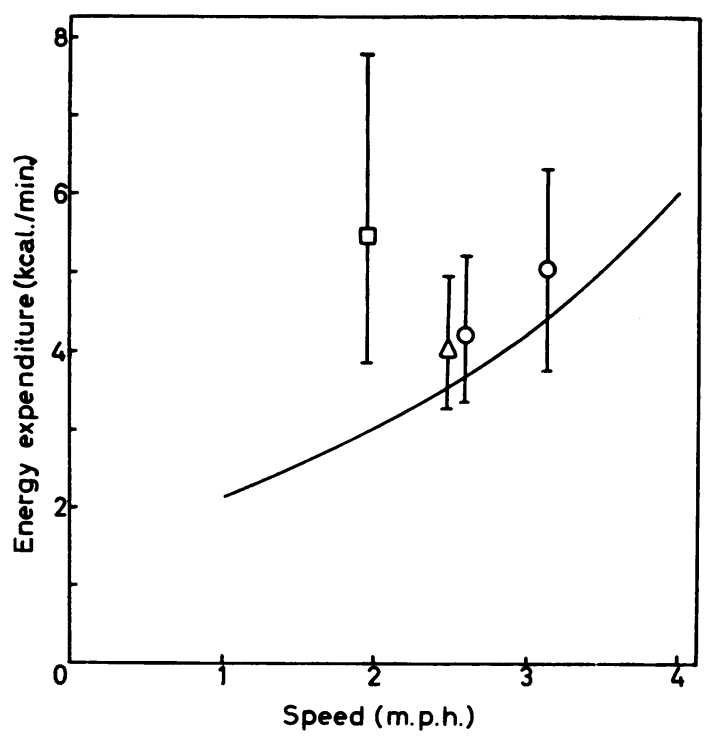

Fig. 5.-Level walking: average energy expenditure, with ranges, of miners walking underground on the level, with good underfoot conditions.

O Normal posture (slow pace nine measurements, quick pace 20). $\Delta$ Slightly stooped (12), $\square$ fully stooped (21)

The complete line is taken from the review by Passmore and Durnin (1955) and represents the average of the results of treadmill walking from five laboratories.

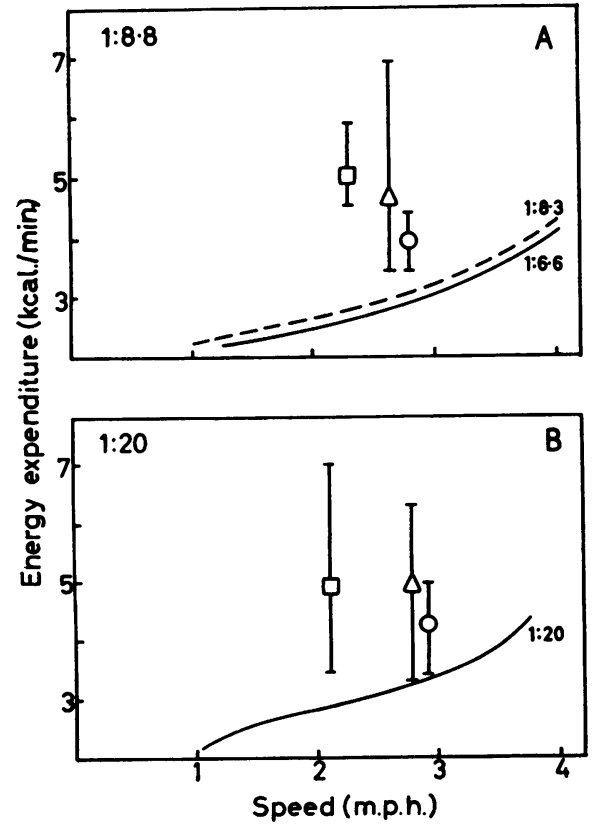

FIG. 7

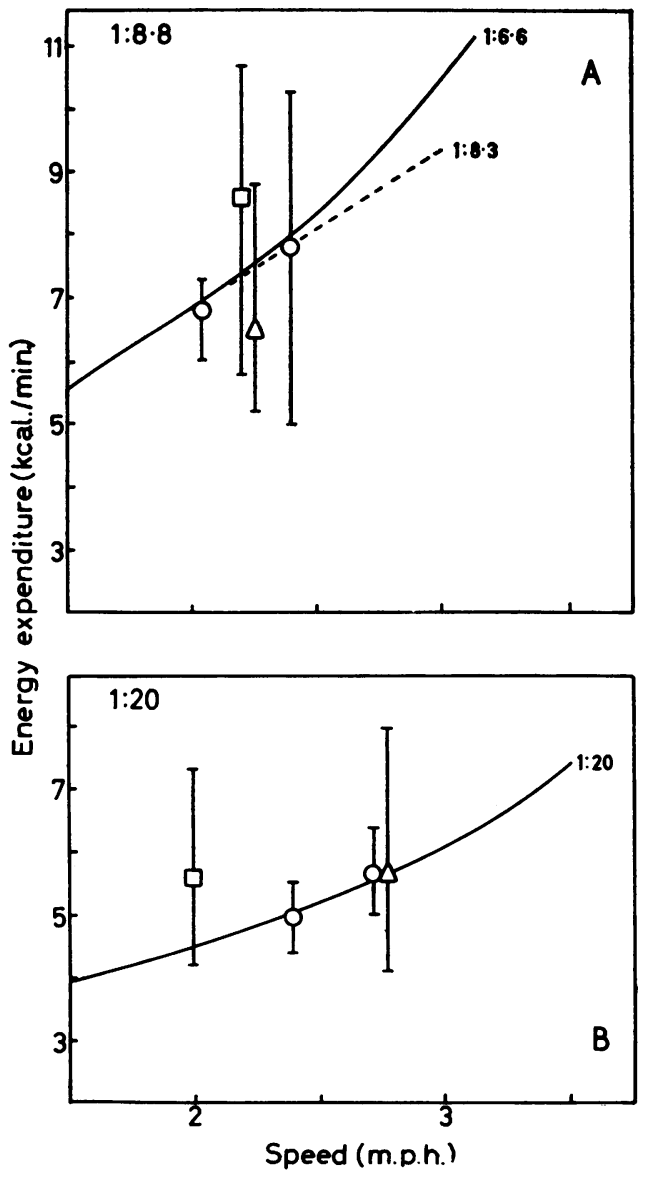

FIG. 6

FIG. 6.-The average energy expenditure, with ranges, of miners walking uphill underground on two gradients:

A: - Slope $1: 8 \cdot 8$, with bad underfoot conditions. $O$ normal posture (four and 17 measurements); $\Delta$ slightly stooped (11); $\square$ fully stooped (14)

B: - Slope 1:20, with "average" underfoot conditions. $\bigcirc$ normal posture (four and 10 measurements; $\Delta$ slightly stooped (nine); $\square$ fully stooped (11)

The complete lines have been constructed from the results of The complete lines have been constructed from the results of four subjects (Marga A: - Slope 1 : 6.6. 20

B: The broken line has been constructed from the results of two subjects (Cotes and Meade, 1960) walking uphill on a treadmill of slope $1: 8 \cdot 3$

FIG. 7.-The average energy expenditure, with ranges, of miners walking downhill on two gradients

A: - Slope $1: 8 \cdot 8$, with bad underfoot conditions. normal posture (five measurements); $\Delta$ slightly stooped (10); $\square$ fully stooped (five).

B: - Slope 1:20, with "average" underfoot conditions.

Normal posture (seven measurements); $\Delta$ slightly stooped (nine); $\square$ fully stooped (11).

(nine); $\square$ fully stooped (11). four subjects (Margaria, 1938) walking downhill on a treadmill: four subjects (Margaria, A: $\longrightarrow$ Slope $1: 6.6$.

B: The broken line has been constructed from the results of one subject (Cotes and Meade, 1960) walking downhill on a treadmill of slope $1: 8 \cdot 3$ 
by assuming that the difference between the data of this survey and laboratory data will be the same at all "normal" speeds for that task, and so appropriately corrected laboratory data may be used. This principle will be used here for estimating the effects of stooping on energy expenditures at a given speed of walking. The values used for the stooped posture, shown in the figures and in Table 3, will be compared with values for normal posture walking estimated by extrapolation, using Figs. 5, 6, and 7, from the speeds at which they were actually measured to the same speed as that at which stooped walking was measured.

The full stoop was thus found to increase the energy expenditure by an average of approximately $60 \%$ above the estimate for normal posture after adjustment to the speed of the stooping posture, i.e. from $3.2 \mathrm{kcal} . / \mathrm{min}$. to $5.6 \mathrm{kcal}$./min. (see Fig. 5). This percentage rise showed large differences between individuals; for some men it was only $30 \%$ and for others $110 \%$. Part of this variation is probably due to small differences in each man's degree of stooping; such differences are difficult to control or to define. If the energy expenditure of level walking with a slight stoop is compared with the estimated energy expenditure of walking normally at the same speed, then no difference in energy expenditure is found.

The differences in energy expenditure with and without a stoop vary with the gradient of walking. Thus the slight stoop when walking downhill increased the energy expenditure by about $1 \mathrm{kcal} . /$ min. compared with normal posture at the same pace; on the level and up a gradient of $1: 20$ the half stoop had no effect, while up the $1: 8 \cdot 8$ gradient it decreased the energy expenditure by about $1 \mathrm{kcal} . /$ $\mathrm{min}$. The full stoop increased the energy expenditure when walking downhill by about $1.5 \mathrm{kcal}$./min. compared with normal posture at the same pace; on the level there was an increase of about $2.5 \mathrm{kcal} . / \mathrm{min}$., and uphill an increase of about $1 \mathrm{kcal} . / \mathrm{min}$.

Effects of Age, Height, and Weight.-For those tasks that were carried out by a number of subjects, an assessment was made of the associations between the energy expended by the individual subjects and their ages, heights, and weights. For walking tasks, a small positive association with weight similar in order to that found by Garry et al. (1955) was the only positive finding. For shovelling the only effect was that of one subject, $Q$, six years older than any of the other subjects, who had a lower energy expenditure for nominally the same rate of work; although it is possible that this is an effect of age it is also possible that this subject took a lighter shovel-load than the others.

\section{Discussion}

In this investigation the emphasis has been put on the determination of the energy expenditure of the important tasks underground measured at different speeds and in a variety of postures; the intention, which has been achieved, was to provide a suitable basis of information so that the energy cost for any given period of time during actual mining practice may be estimated with some reliability from an assessment of the amount of time spent at each of the component tasks during that period. The information so provided seems to be adequate for most purposes, and where it was reasonable to compare results, ours are similar to those of Garry et al. (1955). Some of the findings obtained in this survey require further comment, particularly with regard to discrepancies with, or similarities to, the results of other workers.

Loading and Hewing.-The regression lines relating energy expenditure to the speed of shovelling, which are quite different for the two postures, standing and kneeling, ought to be of use in the estimation of energy expenditure in the practical situation. The difference between the regression lines is such that with a rise in rate of shovelling for the kneeling miner there is a notable rise of energy expenditure, whereas for the miner working on his feet the rate of shovelling has only a small effect on energy expenditure. If any theoretical interpretations of these relationships are attempted, it must be remembered that it was neither possible nor desirable to control the weight of each shovel-load of coal; the assumption that the collier will normally work with a well-loaded shovel was supported by the occasional weighing of sample shovel-loads of coal.

The value of $7.0 \mathrm{kcal} . / \mathrm{min}$., which corresponds to the most common rate of shovelling both for the kneeling and standing postures in production conditions, compares well with the average value of $7 \cdot 1$ kcal./min. obtained from East Fife. The distance and height of throw were kept constant in this present investigation, since it has been shown (e.g. Lehmann, 1953), that these parameters will vary the energy expenditure. There are no other data for coal loading with which to compare the present results; Garry et al. (1955) have reviewed the older surveys which are no longer considered relevant.

The energy expenditure of hewing was $6 \cdot 1 \mathrm{kcal}$./ min., except for the men working while lying on their sides, where it was only $5.3 \mathrm{kcal} . / \mathrm{min}$. Both of these values are somewhat less than that of $7.0 \mathrm{kcal} . /$ min., reported by Garry et al. (1955) from results obtained in East Fife. It appears that when the 
TABLE 4

ENERGY EXPENDITURE VALUES ESTIMATED OR TAKEN FROM PREVIOUS SURVEYS AND USED HERE TO CALCUFROM PREVIOUS SURVEYS AND USED HERE TO CALCU

\begin{tabular}{|c|c|c|}
\hline Occupation & $\begin{array}{c}\text { Energy } \\
\text { Expenditure } \\
\text { (kcal./min.) }\end{array}$ & Source \\
\hline \multirow{2}{*}{$\begin{array}{l}\text { Standing } \\
\text { Sitting } \\
\text { Crawling on level } \\
\text { Crawling uphill } \\
\text { Crawling downhill } \\
\text { Preparatory activities at } \\
\text { coal-face } \\
\text { Girdering }\end{array}$} & $\begin{array}{r}1 \cdot 7 \\
1.6 \\
7.0 \\
10 \cdot 8 \\
5.5\end{array}$ & $\begin{array}{l}\text { Garry et al. (1955) } \\
\text { Garry et al. }(1955) \\
\text { *Garry et al. }(1962) \\
{ }^{*} \text { Garry et al. }(1962) \\
\text { *Garry et al. }(1962)\end{array}$ \\
\hline & $\begin{array}{l}2 \cdot 7 \\
6 \cdot 4\end{array}$ & $\begin{array}{l}\text { Estimated } \\
\text { †ean of: } \\
5.7 \text { of Garry et al. (1955) } \\
7.1 \text { of Moss (1935) }\end{array}$ \\
\hline
\end{tabular}

*Results obtained from limited amount of data (R. G. Garry, R. Passmore, G. M. Warnock, and J. V. G. A. Durnin, 1962, personal communication).

TThe value for girdering has been treated as the average of two different surveys since the nature of the work involved varies greatly in different situations, in ways difficult of precise definition, so that the average of the two surveys probably gives a better result than that of either on its own.

TABLE 5

SIMPLIFIED TIME AND ENERGY EXPENDITURE ANALYSIS OF A TYPICAL SHIFT OF WORK

\begin{tabular}{c|l|c}
\hline $\begin{array}{c}\text { Percentage of } \\
\text { Shift Time }\end{array}$ & Task & $\begin{array}{c}\text { Percentage of } \\
\text { Energy Expenditure } \\
\text { of Shift }\end{array}$ \\
\hline 30 & Loading & 47 \\
15 & Walking & 16 \\
40 & Sitting or standing & 16 \\
7 & Girdering & 10 \\
3 & Hewing & 5 \\
5 & Other activities & 6 \\
\hline
\end{tabular}

miner is lying on his side, whether hewing or loading coal, he expends less energy than when he is in the more conventional postures. The observers did however have the impression that much less coal was being moved.

Walking.-The present results for normal posture level walking are on average $0.5 \mathrm{kcal} . / \mathrm{min}$. higher than the equivalent laboratory data for treadmill walking (Fig. 5). This can be accounted for quantitatively by differences in the weights carried by the laboratory subjects and the miners (Mahadeva, Passmore, and Woolf, 1953): the miners wore heavier clothing, battery, lamp, helmet, and heavier footwear which Turrel and Robinson (1949) have shown to be particularly effective in increasing the energy expenditure of walking. These items represent an "effective" additional weight to the miner of some $11 \mathrm{~kg}$. which is sufficient to account for the observed difference. Underfoot conditions were good for level walking and consequently could have had no effect upon the energy expenditure (Ralston, 1960).

Walking in the normal posture on the gradients cannot be compared with the laboratory data quite as critically as it can be with those for level walkıng for two reasons: (i) laboratory data on downhill walking are not plentiful, so that the results are compared with a smaller number of results than are those for level walking, and (ii) as frequently occurs on inclines underground, underfoot conditions were either bad or "average for underground" (Fig. 3), which could affect the energy cost (cf. Passmore and Durnin, 1955). Nevertheless, the two sets of results are in close agreement.

Full stoop level walking increased the energy expenditure by only $60 \%$ with wide individual variations from $30 \%$ to $110 \%$, surprisingly little compared with the increment of $264 \%$ found by Bedford and Warner (1955) who studied only one subject in a laboratory. It is suspected that a large part of the difference between the two sets of results may lie in the interpretation of "full stoop", as in the field this is probably a little kinder than in the laboratory. Fig. 3 shows the stoop adopted in the present investigation, which miners consider to be the lowest they would ever stoop without going down on all fours; the observers ensured that the stoop was maintained during the latter part of the warming-up period and throughout the sampling periods. Level walking with a slight stoop gave no increment of energy expenditure over level walking with no stoop, yet Bedford and Warner (1955) reported an increment of $43 \%$. The suggestions made above for the full stoop are again considered as the most probable explanation.

The Complete Shift.-Thirty-one time analyses were made of complete shifts of underground work at 16 different coal-faces in different parts of the country in the first stage of this programme. Of these, 22 were of shifts of work where the miner completely cleared his stint of coal. In the other cases the miner was unable to do so because of setbacks created by failures of the haulage system. The total energy expenditures for each of the 22 completed shifts have been computed from these time analyses, using energy expenditure values published here and elsewhere. For walking, loading, and hewing in the different postures, the results given in Table 2, and Figs. 4, 5, 6, and 7 were used; for other tasks the values given in Table 4 were used, from the sources stated.

For illustration Table 5 shows mean values from these computations for the 22 shifts. It can be seen that the tasks studied in the present investigation (walking, hewing, and loading) account for $68 \%$ of the estimated total energy expended in the shift. Of the values obtained from other sources, the most important are for sitting and standing, which together contribute $16 \%$ of the total energy expenditure 
of the shift and for girdering which accounts for $10 \%$.

The energy expenditure values for each of the component tasks, applied to the 22 time analyses where the pattern of work varied considerably, led to estimates of total energy expenditure of from 1,587 to $2,394 \mathrm{kcal} . / \mathrm{shift}$. The average value of $2,002 \mathrm{kcal}$. for a shift of seven hours and 57 minutes is virtually identical with the average value of 1,990 $\mathrm{kcal}$. previously found for a shift of seven hours and 44 minutes: the corresponding hourly rates of energy expenditure are $252 \mathrm{kcal}$./hour for the present survey and $257 \mathrm{kcal}$./hour for that of Garry et al.

Mechanization in the collieries is now progressing rapidly, and some $75 \%$ of all the coal produced in this country is now loaded by machine. Consequently data concerning the manual labour of mining might well be expected to become less important. However, any physiological criterion intended to determine environmental conditions for mining must be set at a level suitable for men with the highest handicap of metabolic heat, and at a mechanized coal-face the men concerned are those who still have to work with a pick and shovel at parts of the face, such as the "stable ends" which are inaccessible to the machine.

The slow return of results for many observer manhours in determinations of energy expenditure by indirect calorimetry under field conditions is well known. Even then, the results show a large variance between subjects and a large variance between repeated performances by the same subject, since it is difficult even under the controlled conditions of this survey to regulate the task accurately. Consequently, it is tempting to accept simpler techniques in the practical situation. Durnin and Edwards (1955) have suggested the usefulness of estimating energy expenditure from pulmonary ventilation: their proposals are discussed by Liddell (1962), who examined in detail the data presented here and compared them with results of other workers. Liddell comes to the conclusion that the proposal to use pulmonary ventilation as a measure of energy cost for different tasks is inadvisable.
Records are now being collected from other coalfaces under production conditions in different parts of the country; the posture of the working man and his rate of work are again being defined. It is hoped that these records will substantiate and extend those of this survey, and will allow the examination of hour-to-hour variations.

A survey of this nature is not possible without the help of many people. We were very fortunate in receiving so much help from everybody we met at Waterloo Colliery, and in other parts of South Wales, which allowed this survey to run as smoothly as it did. We must particularly thank Dr. T. H. Jenkins, Mr. D. H. Thomas, Mr. Wallace and his staff, and Mr. D. D. Evans. We are greatly indebted to the 14 miners of Waterloo Colliery who volunteered their services as subjects and gave their complete and wholehearted co-operation.

We should like to express our thanks to Dr. J. S. Weiner for critical discussion; and to Mr. F. D. K. Liddell for the complete statistical analysis of the results and for much valuable discussion.

We are very grateful for the valuable help given underground at various times by colleagues and friends: Dr. K. J. Collins, Mr. G. W. Crockford, Mr. G. Jenkins, and Mr. J. Williams, and for the photography underground to Mr. S. P. Prestidge.

\section{REFERENCES}

Bedford, T., and Warner, C. G. (1955). Brit. J. industr. Med., 12,

290.,

Durnin, J.' V. G. A., and Edwards, R. G. (1955). Quart. J. exp.

Physiol., 40, 370.
Garry, R. C., Passmore, R., Warnock, G. M., and Durnin, J. V. G. A. (1955). Spec. Rep. Ser. med. Res. Coun. (Lond.), No. 289.

Granati, A., and Busca, L. (1941). Quad. Nutr., 8, 1. Kofrányi, E. and Michaelis, H. F. (1940). Arbeitsphysiologie, 11 ,

Lehmann, G. (1953). Praktische Arbeitsphysiologie. Thieme, Stuttgart. , Müller, E. A., and Spitzer, H. (1950). Arbeitsphysiologie, 14,

Liddell, F. D. K. (1962). J. appl. Physiol. In the press.

Liddel, F. R. (1960). Industr. Med. Surg., 29, 515.

Lind, A. R. (1960). Industr. Med. Surg., 29, 515.

Mahadeva, K., Passmore, R., and Woolf, B. (1953). ibid., 121, 225.

Margaria, R. (1938). Atti r. Accad. naz. (Mem. cl. Sci. bis. mat. nat.) Lincei, ser. 6, 7, 299.

Moss, K. N. (1935). Trans. Instn Min. Engnrs, Lond., 89, 132.

Passmore, R., and Durnin, J. V. G. A. (1955). Physiol. Rev., 35, 801.

Ralston, H. J. (1960). J. appl. Physiol., 15, 1156.

Turrel, E. S., and Robinson, S. (1949). Quoted in Physiology of Heat Regulation and the Science of Clothing, p. 349, ed. L. H. Newburgh. Saunders, Philadelphia.

Wolff, H. S. (1958). Quart. J. exp. Physiol., 43, 270. 


\section{A P P E N D I X}

A: ENERGY EXPENDED SHOVELLING COAL

$\mathrm{kcal}$./min. and in brackets rate in shovel-loads per min.

\begin{tabular}{|c|c|c|c|c|c|c|c|c|c|c|c|c|c|c|c|c|c|}
\hline \multirow{2}{*}{$\frac{\text { Subject }}{\mathrm{C}}$} & \multicolumn{8}{|c|}{ Standing } & \multicolumn{5}{|c|}{ Kneeling } & \multicolumn{2}{|c|}{ Lying } & \multicolumn{2}{|c|}{$\begin{array}{l}\text { "Scooping" } \\
\text { Shovelling }\end{array}$} \\
\hline & $\begin{array}{c}5.9 \\
(15) \\
6.9\end{array}$ & $\begin{array}{l}6 \cdot 8 \\
(16) \\
6 \cdot 8\end{array}$ & $\begin{array}{c}7 \cdot 2 \\
(26) \\
6 \cdot 3\end{array}$ & $\begin{array}{c}6.2 \\
(28) \\
7.3\end{array}$ & $\begin{array}{l}6.0 \\
(29) \\
8 \cdot 7\end{array}$ & $\begin{array}{c}8.2 \\
(40) \\
7.9\end{array}$ & $\begin{array}{l}8.6 \\
(42) \\
7.8\end{array}$ & & $\begin{array}{c}5 \cdot 2 \\
(21) \\
6 \cdot 3\end{array}$ & $\begin{array}{r}5.3 \\
(21) \\
6.9\end{array}$ & $\begin{array}{r}5.0 \\
(22) \\
8.8\end{array}$ & $\begin{array}{c}7 \cdot 3 \\
(33) \\
9 \cdot 8\end{array}$ & $\begin{array}{l}8 \cdot 1 \\
(40)\end{array}$ & $\begin{array}{c}5.1 \\
(25) \\
6.1\end{array}$ & $\begin{array}{l}5.4 \\
(25) \\
5.9\end{array}$ & $\begin{array}{c}7.7 \\
(50) \\
8.0\end{array}$ & $\begin{array}{l}7 \cdot 2 \\
7 \cdot(9)\end{array}$ \\
\hline I & $\begin{array}{l}(21) \\
4.8 \\
(15)\end{array}$ & $\begin{array}{l}(22) \\
4.9 \\
(15)\end{array}$ & $\begin{array}{r}4.6 \\
(21)\end{array}$ & $\begin{array}{c}(30) \\
5.5 \\
(21)\end{array}$ & $\begin{array}{l}(31) \\
6.8 \\
(28)\end{array}$ & $\begin{array}{l}(37) \\
6.4 \\
(34)\end{array}$ & $\begin{array}{r}(42) \\
6.2 \\
(43)\end{array}$ & & $\begin{array}{c}(22) \\
3.9 \\
(16) \\
6 \cdot 1 \\
(26)\end{array}$ & $\begin{array}{c}(23) \\
3.9 \\
(16) \\
5.5 \\
(28)\end{array}$ & $\begin{array}{c}(40) \\
5.0 \\
(20) \\
5.5 \\
(32)\end{array}$ & $\begin{array}{c}(44) \\
4 \cdot 1 \\
(21) \\
6 \cdot 5 \\
(33)\end{array}$ & $\begin{array}{l}6 \cdot 8 \\
(25)\end{array}$ & $\begin{array}{c}(29) \\
4 \cdot 6 \\
(22) \\
5 \cdot 3 \\
(27)\end{array}$ & $\begin{array}{c}(31) \\
4 \cdot 7 \\
(23) \\
5 \cdot 2 \\
(28)\end{array}$ & & \\
\hline $\mathbf{T}$ & $\begin{array}{c}5.4 \\
(18)\end{array}$ & $\begin{array}{c}5.6 \\
(18)\end{array}$ & $\begin{array}{l}6.8 \\
(19)\end{array}$ & $\begin{array}{r}6 \cdot 6 \\
(30)\end{array}$ & $\begin{array}{c}7 \cdot 2 \\
(30)\end{array}$ & $\begin{array}{l}8 \cdot 8 \\
(45)\end{array}$ & & & $\begin{array}{l}5.8 \\
(20)\end{array}$ & $\begin{array}{l}5 \cdot 4 \\
(21)\end{array}$ & $\begin{array}{l}7.9 \\
(35)\end{array}$ & $\begin{array}{l}9.4 \\
(35)\end{array}$ & & $\begin{array}{r}6.2 \\
(19)\end{array}$ & $\begin{array}{l}4.8 \\
(20)\end{array}$ & $\begin{array}{r}8.2 \\
(45)\end{array}$ & $\begin{array}{r}6.4 \\
(54)\end{array}$ \\
\hline $\mathbf{F}$ & $\begin{array}{l}5.9 \\
(20)\end{array}$ & $\begin{array}{l}6 \cdot 5 \\
(21)\end{array}$ & $\begin{array}{l}8.2 \\
(34)\end{array}$ & $\begin{array}{l}6.5 \\
(38)\end{array}$ & & & & & & & & & & & & & \\
\hline H & & $\begin{array}{l}7 \cdot 8 \\
(17)\end{array}$ & $\begin{array}{l}6 \cdot 7 \\
(20)\end{array}$ & & & & & & & & & & & & & & \\
\hline 0 & $\begin{array}{c}5.0 \\
(25)\end{array}$ & $\begin{array}{l}6 \cdot 3 \\
(25)\end{array}$ & $\begin{array}{l}6.4 \\
(37)\end{array}$ & $\begin{array}{l}7.4 \\
(38)\end{array}$ & $\begin{array}{l}8 \cdot 2 \\
(41)\end{array}$ & $\begin{array}{l}8 \cdot 7 \\
(42)\end{array}$ & $\begin{array}{l}8 \cdot 7 \\
(44)\end{array}$ & & & & & & & & & & \\
\hline $\mathbf{P}$ & $\begin{array}{l}6.9 \\
(15) \\
8.3\end{array}$ & $\begin{array}{l}8.4 \\
(15) \\
7.8\end{array}$ & $\begin{array}{l}9.8 \\
\text { (15) }\end{array}$ & $\begin{array}{l}7.6 \\
\text { (16) }\end{array}$ & $\begin{array}{l}6.3 \\
\text { (16) }\end{array}$ & $\begin{array}{l}7.8 \\
(23)\end{array}$ & $\begin{array}{l}8.8 \\
(28)\end{array}$ & & & & & & & & & . & \\
\hline $\mathbf{Q}$ & $\begin{array}{l}\text { (30) } \\
3.9\end{array}$ & $\begin{array}{l}(35) \\
4 \cdot 6\end{array}$ & 4.4 & $5 \cdot 1$ & 6.4 & 6.2 & 6.7 & & & & & & & & & & \\
\hline $\mathbf{S}$ & $\begin{array}{l}(19) \\
7.6 \\
(17)\end{array}$ & $\begin{array}{c}(23) \\
5.4 \\
(19)\end{array}$ & $\begin{array}{c}(27) \\
6 \cdot 0 \\
(20)\end{array}$ & $\begin{array}{c}(28) \\
6.2 \\
(20)\end{array}$ & $\begin{array}{l}(38) \\
7.4 \\
(23)\end{array}$ & $\begin{array}{l}(44) \\
8.7 \\
(23)\end{array}$ & $\begin{array}{c}(47) \\
6 \cdot 2 \\
(29)\end{array}$ & $\begin{array}{l}6 \cdot 3 \\
(34)\end{array}$ & & & & & & & & & \\
\hline
\end{tabular}

B: ENERGY EXPENDED WALKING UPHILL

kcal./min., and in brackets, speed in m.p.h.

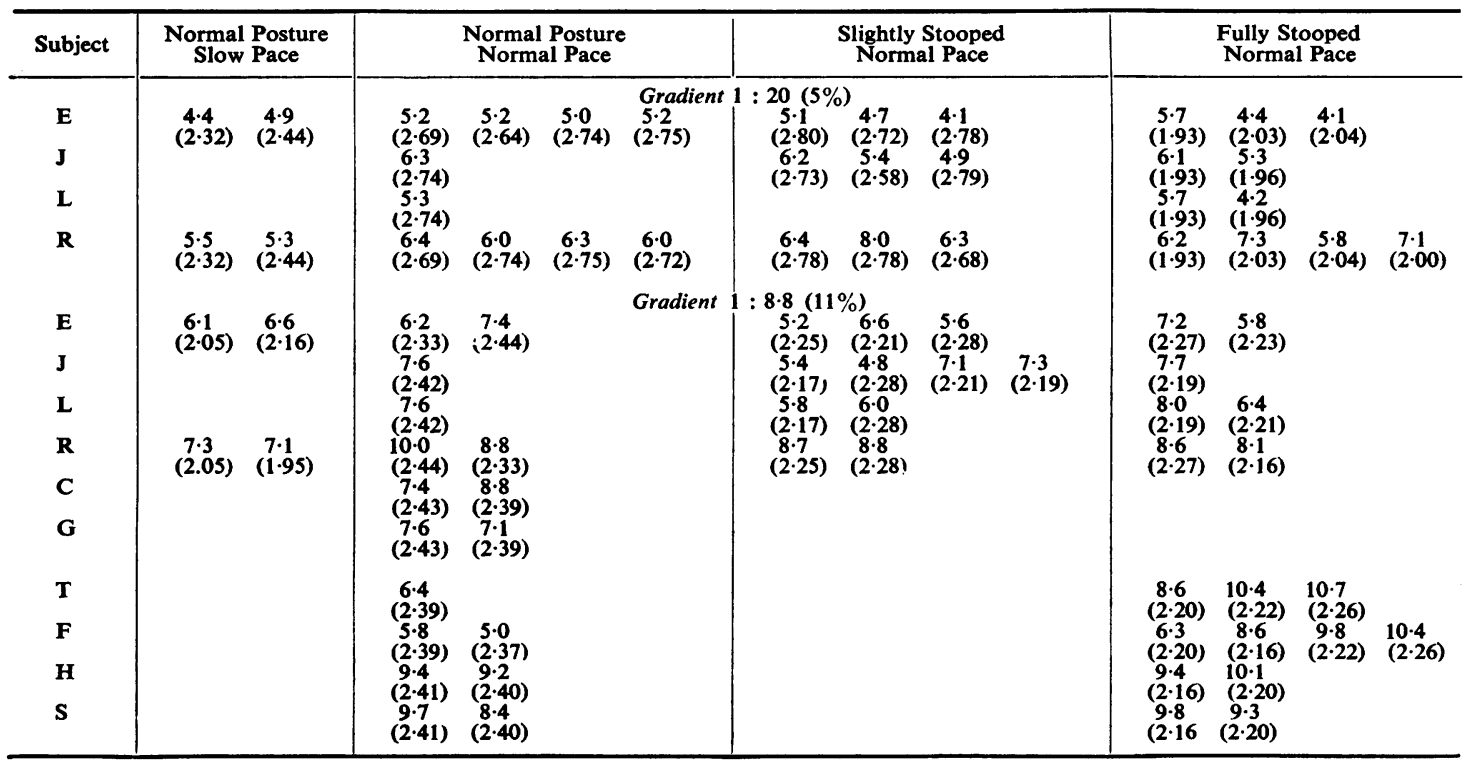


C: ENERGY EXPENDED WALKING DOWNHILL

kcal./min., and in brackets speed in m.p.h.

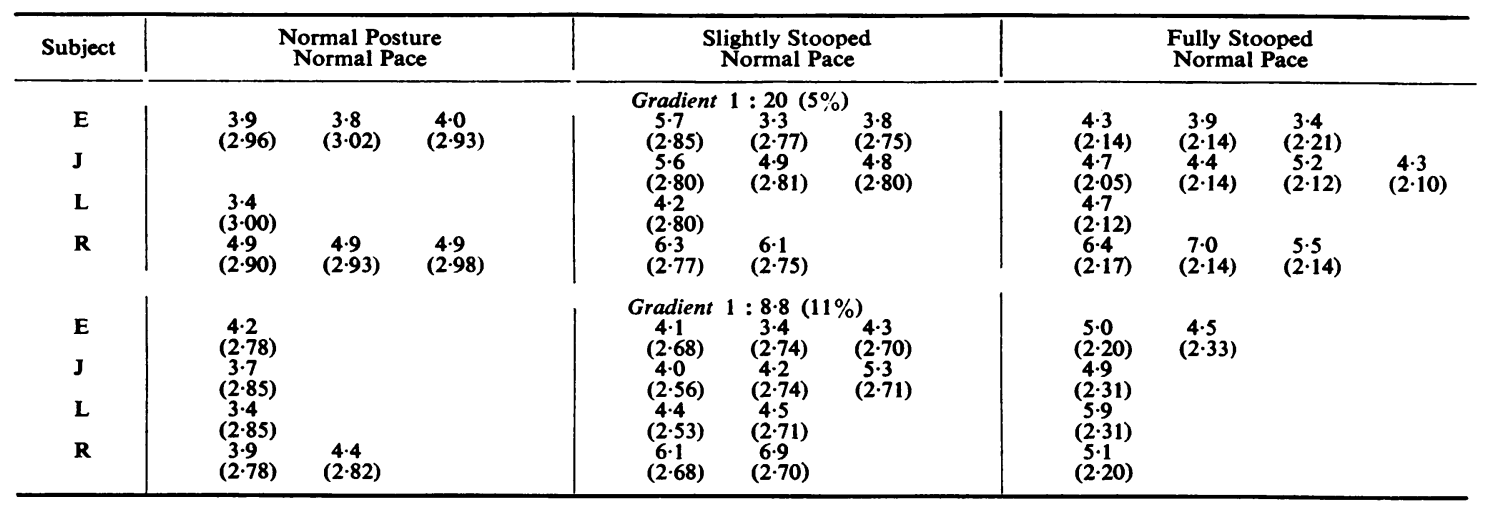

D: ENERGY EXPENDED WALKING ON THE LEVEL kcal./min., and in brackets speed in m.p.h.

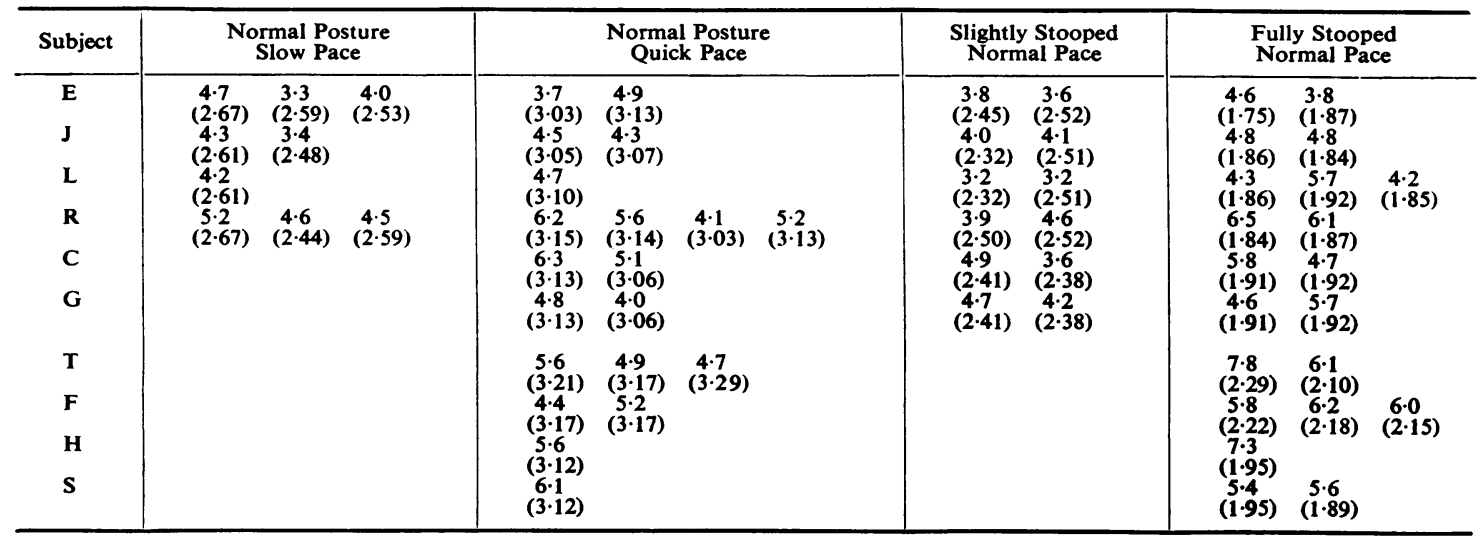

E: ENERGY EXPENDED HEWING COAL (kcal./min.)

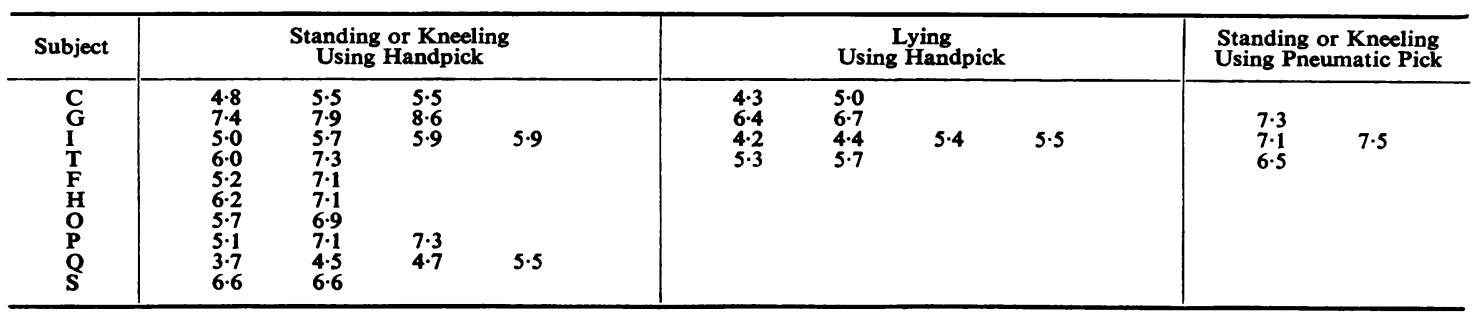

